\title{
Outcome for esophageal cancer following treatment with chemotherapy and radiotherapy but not esophagectomy: Nonsurgical treatment of esophageal cancer
}

\author{
This article was published in the following Dove Press journal: \\ Clinical and Experimental Gastroenterology \\ 23 July 2009 \\ Number of times this article has been viewed
}

\author{
Urs Zingg ${ }^{1,2}$ \\ Dennis DiValentino' \\ Alexander McQuinn' \\ Ahmad Mardzuki' \\ Sarah K Thompson ${ }^{2}$ \\ Christos S Karapetis ${ }^{1,3}$ \\ David I Watson' \\ 'Flinders University Department \\ of Surgery, Flinders Medical \\ Centre, Bedford Park, South \\ Australia, Australia; ${ }^{2}$ Discipline \\ of Surgery, University of Adelaide, \\ Adelaide, South Australia, Australia; \\ ${ }^{3}$ Department of Medical Oncology, \\ Flinders Medical Centre, Bedford \\ Park, South Australia, Australia
}

Background: More than $50 \%$ of patients with esophageal cancer are not suitable for surgery. The aim of this study was to analyze the outcome of patients undergoing standard nonsurgical treatment.

Methods: Data of all patients undergoing nonsurgical treatment for esophageal cancer were identified from a prospective database.

Results: Seventy-five patients were treated for localized disease, and 52 for metastatic disease at diagnosis. Except for age, which was higher in patients without metastases, there were no significant differences between the patients with vs. without metastatic disease. Kaplan-Meier analysis showed a median survival of 10.8 months for all patients. There was a significant difference in survival $(\mathrm{p}<0.001)$ between the groups with versus without metastases, with median survival in the patients without metastases 13.6 months versus 6.5 months in patients with metastases. Patients undergoing nonsurgical treatment for localized disease had a fiveyear survival of $12 \%$. No significant difference between adenocarcinoma and squamous cell carcinoma was identified. Subanalysis of patients who received chemoradiotherapy revealed similar results to the overall group of patients.

Conclusion: In patients with localized disease at diagnosis, long-term survival can be achieved in some patients, whereas five-year survival is rare in patients who present with metastatic disease.

Keywords: nonsurgical treatment, esophageal cancer, chemoradiotherapy, metastases, survival

\section{Introduction}

Worldwide, esophageal cancer is the sixth leading cause of death from cancer. While the incidence of adenocarcinoma is increasing, the incidence of squamous cell carcinoma (SCC) is stable. ${ }^{1}$ The cornerstone of curative treatment has been surgery. However, for a variety of reasons, the majority of patients with esophageal cancer are actually not suitable for esophagectomy. More than 50\% have locally advanced, unresectable or metastatic tumors at diagnosis. ${ }^{2}$ Other reasons which preclude esophagectomy include old age, comorbidity, or refusal by the patient. ${ }^{3}$

The mainstay of nonsurgical treatment is chemotherapy (CT) or radiotherapy (RT), either alone or in combination (chemoradiotherapy; CRT). In comparative studies which included patients with International Union against Cancer (UICC) stages I to III, combined therapy has been shown to be more effective than single modality therapy. ${ }^{4-6}$ Only one study has shown no advantage for CRT compared to RT. ${ }^{7}$
Correspondence: Urs Zingg

Oesophagogastric and Professorial Unit, Discipline of Surgery, University of Adelaide, Royal Adelaide Hospital, North Terrace, Adelaide 5000 SA, Australia

Tel +61882224437

Fax +61882225895

Email uzingg@uhbs.ch 
Other noncomparative studies excluding UICC stage IV patients have shown two-year survival rates of up to $26 \%$, whereas UICC stage IV patients are reported to have median survival of between 5 and 12 months following these treatments. ${ }^{8-13}$

Standard CRT treatment usually entails 5-fluorouracil (5-FU) and cisplatin in variable dosages, combined with 50 to 64 Gy of radiation. ${ }^{6}$ However, a substantial number of other agents such as docetaxel, capecitabine, or bortezomib have been tested in the settings of advanced or metastatic esophageal cancer. ${ }^{9,11,12}$ The groups of patients studied in various clinical trials differ in terms of stage and histological subtype. Additionally, most reports only describe small numbers of patients, and many of the studies were funded by the manufacturers of the CT agents evaluated in these studies. These factors make it difficult to know the actual outcome for nonsurgical treatment in day to day clinical practice, ie, outside clinical trials.

A number of factors have been shown to predict survival in advanced esophageal cancer. These include UICC stage, performance status, weight loss, and presence or absence of metastasis. The stage of the cancer, and in particular the presence of metastatic disease, is the single strongest predictor. ${ }^{14,15}$ The influence of other factors, such as histological type, has been less well established. ${ }^{2,16}$

Many previous studies have reported outcomes for patients undergoing surgical resection for esophageal cancer. However, the outcome of such studies does not inform clinical decision making for the majority of patients who present to surgeons with esophageal cancer. Hence, in this study we sought to determine the outcome for patients who underwent treatment of esophageal cancer with conventional CT and RT, but not surgical resection, in our departments. We also determined the specific outcomes for patients with and without metastatic disease, and in patients with different histological subtypes.

\section{Patients and methods}

From 1999 onwards, details for patients with esophageal cancer in two university hospitals and associated private hospitals in South Australia were prospectively entered into a database (FileMaker Pro, Version 8; FileMaker Inc., Santa Clara, CA, USA). For this study, all patients who underwent nonsurgical treatment for esophageal cancer over a sevenyear period from March 2001 until February 2008 were identified and their outcome was retrospectively determined. Patients presenting with tumors of the proximal stomach and gastroesophageal junction were excluded.
Patients were not considered for surgical resection if any of the following criteria were met: metastatic cancer, significant comorbidity (cardiac, pulmonary, renal, or hepatic) which precluded esophagectomy, age 80 years or older, or patient refused surgery. The decision regarding operability was made by a multidisciplinary group, consisting of surgeons, radiation oncologists, and medical oncologists. Some patients were managed with an esophageal stent, although our preference was to use CRT or RT for treatment unless contraindicated. Metastasis was defined according the UICC TNM classification (6th edition). Metastasis in the celiac lymph nodes from tumors of the lower esophagus were considered to be $\mathrm{M}$ positive (M1a). In tumors of the upper third of the esophagus, metastasis to the cervical lymph nodes was considered to be $\mathrm{M}$ positive (M1a). Patients with UICC stage IV were classified into the metastatic group, whereas patients with UCC stages I-III were classified into the nonmetastatic group. We did not further stratify the nonmetastatic group according lymph node status as the resulting cohorts were too small for meaningful analysis.

All patients were staged with computed tomography scans (chest and abdomen) and upper endoscopy with biopsy. Endoscopic ultrasound was readily available at only one of the two treatment sites, and therefore used for staging in only 37 patients. From 2002, positron emission tomography was also readily available at only one of the two treatment sites, and it was used for clinical staging in 36 of the patients.

Demographic details, comorbidity, tumor pathology, clinical outcome such as palliation, morbidity, and mortality were obtained from the database. All data was verified and any missing data retrieved from the case records. Treatment-elated morbidity was defined as hepatic (increase of liver function tests; alanine aminotransferase $>50 \mathrm{iU} / 1$, aspartate aminotransferase $>40 \mathrm{iU} / 1$ and gamma-glutamyl transferase $>60 \mathrm{iU} / \mathrm{l}$ ), renal, radiation esophagitis, neutropenia requiring treatment and others such as thrombosis or nausea. Dysphagia was defined as the clinical symptom of difficulty to swallow. Clinical followup after treatment was performed by the medical oncologists. However, after transfer of care to palliative care, this follow-up normally stopped. Survival data was obtained from the South Australia State Cancer Registry and the South Australia State Births, Deaths and Marriages Registry.

\section{Nonsurgical treatment protocols}

Localized esophageal cancer was defined as disease that could be treated using a single RT field and was UICC stage I-III. The standard treatment for these patients was combined CRT. RT was given at a dose of $1.8 \mathrm{~Gy}$ per fraction once per day, to a total of $50.4 \mathrm{~Gy}$, depending on tolerance. The CT, 
consisted of cisplatin administered at a dose of $80 \mathrm{mg} / \mathrm{m}^{2}$ over one hour with a standard cisplatin hydration protocol, and a 96-hour infusion of 5-FU administered at $1000 \mathrm{mg} / \mathrm{m}^{2}$ per 24 hours. CT was administered during week 1 and week 5 of the RT course. Patients that were able to tolerate further CT were treated with two additional courses of CT after the completion of RT, in keeping with the RTOG protocol. ${ }^{4}$ These courses were usually given at week 9 and week 13 of the overall treatment period.

For patients who were not considered suitable for CT, $\mathrm{RT}$ alone was administered. The most common reasons for unsuitability were poor renal function, other comorbidities, poor performance status, and patient preference. In 12 patients $(9.5 \%)$ RT alone at a dose of 2 Gy per fraction with a total 60 Gy over a six-week period was administered.

In general, patients with metastatic disease also received combined CRT treatment. The $\mathrm{CT}$ involved either cisplatin $\left(75-80 \mathrm{mg} / \mathrm{m}^{2}\right.$ ) and 5-FU (96-hour infusion at $800-1000 \mathrm{mg} / \mathrm{m}^{2}$ per 24 hours) or epirubicin $50 \mathrm{mg} / \mathrm{m}^{2}$ on day 1 , cisplatin $60 \mathrm{mg} / \mathrm{m}^{2}$ on day 1 and $5-\mathrm{FU} 200 \mathrm{mg} / \mathrm{m}^{2}$ as a continuous infusion, with cycles repeated every 21 days (ECF). ${ }^{17}$ In 12 patients (23\%), CT alone was given.

As these treatments varied, a subgroup analysis of all patients who received the standard combined CRT protocol was performed.

\section{Statistical analysis}

Survival data was determined from records in the database, the South Australian Cancer Registry and the South Australian Registry of Births, Deaths and Marriages. Comparison of data between the two patient groups was undertaken using Chi-square tests for categorical data, and Mann-Whitney $\mathrm{U}$ tests for nonparametric continuous data sets. Survival was calculated according to the Kaplan-Meier method, and survival differences between groups were determined using the $\log$ rank test. Statistical significance was set at $\mathrm{p}<0.05$. Statistical analyses were performed with MedCalc ${ }^{\circledR}$ (Version 9 for Windows; MedCalc Software, Mariakerke, Belgium).

This study was approved by the Flinders Clinical Research Ethics Committee, and the Royal Adelaide Hospital Clinical Research Ethics Committee.

\section{Results \\ Demographics}

Between March 2001 and February 2008, 149 patients underwent nonsurgical treatment using CT and/or RT, and had details entered into the database. Twenty-two (14.8\%) of these patients were subsequently excluded from analysis because the data available was insufficient for analysis. This meant that 127 patients were included in this study. Of these patients, survival could not be determined in five (3.9\%), as they were lost to follow up. Seventy-five (59.1\%) were treated for localized disease and $52(40.9 \%)$ had metastases at the time of treatment.

Within the group with localized disease, 48 patients $(64 \%)$ were considered to be unfit for surgery due to either comorbidities (44 patients, $58.7 \%$ ) or age (eight patients, $10.7 \%)$. Seven patients $(9.3 \%)$ had a tumor which was deemed to be locally unresectable based on imaging criteria and $16(21.3 \%)$ refused esophagectomy. Of the patients refusing surgery, eight had a locally advanced tumor. There were no early stage (T1 or T2) tumors in this group; all patients were T-stage 3 or 4 . The median patient age was higher in the group without metastases, but otherwise the demographic data in the groups with and without metastatic disease were similar (Table 1). Age was significantly different between groups. A Cox regression analysis showed that age ( $>65$ years versus $\leq 65$ years) was not a predictive factor for survival (hazard ratio $0.72,95 \%$ confidence interval: $0.47-1.10 ; \mathrm{p}=0.132)$.

Overall, $114(89.8 \%)$ patients had dysphagia at the time of diagnosis, $33(26 \%)$ patients had pain, and $11(8.7 \%)$ patients had hemorrhaged from the tumor. There were significant differences between the groups with metastatic versus localized disease for the proportion of patients with pain, and the success of the palliation following treatment (Table 2). Patients receiving only CT without RT $(n=28)$ had similar rates of pretreatment dysphagia (85.7\%). Dysphagia was less palliated with CT alone, with only $11.8 \%$ of patients having a complete palliation, $52.9 \%$ a partial palliation and $35.3 \%$ no palliation. Three of the patients $(10.7 \%)$ treated with CT alone were stented and no patient required dilatations.

\section{Location of metastases}

Concerning the location of distant metastases at the time of treatment, the liver was affected most frequently (20 patients), followed by extra-regional lymph nodes (17 patients), lungs (nine patients), and bone (seven patients). One patient had metastases in the adrenal gland, one in the peritoneal cavity, and one in to the bowel. In six patients, localization of distant metastasis could not be determined at review.

\section{Nonoperative treatment regimens}

Eighty-seven (68.5\%) patients received CRT. Twenty-eight (22\%) received only CT, and $12(9.5 \%)$ only RT. There were significant differences in the distribution of treatment types between the groups with versus without metastatic disease, 
Table I Descriptive parameters of all patients undergoing nonsurgical treatment

\begin{tabular}{|c|c|c|c|}
\hline & Nonmetastatic $n=75$ & Metastatic $n=52$ & $\mathbf{p}$ \\
\hline Median age at diagnosis (range) & $76.3(46.3-90.6)$ & $64.8(32.8-87.8)$ & $<0.00 I^{*}$ \\
\hline Gender & & & 0.224 \\
\hline Male & 51 (68.0\%) & $29(55.8 \%)$ & \\
\hline Female & $24(32.0 \%)$ & $23(44.2 \%)$ & \\
\hline Median BMI (range) & $23.8(15.0-42.9)$ & $25.5(15.0-32.0)$ & 0.414 \\
\hline \multicolumn{4}{|l|}{ Comorbidity } \\
\hline Cardiac & & & 0.511 \\
\hline Yes & $33(44.0 \%)$ & $19(36.5 \%)$ & \\
\hline No & $42(56.0 \%)$ & $33(63.5 \%)$ & \\
\hline Pulmonary & & & 0.117 \\
\hline Yes & $20(26.7 \%)$ & 7 (I3.5\%) & \\
\hline No & $55(73.3 \%)$ & 45 (86.5\%) & \\
\hline Hepatic & & & 0.674 \\
\hline Yes & $3(4.0 \%)$ & $2(3.8 \%)$ & \\
\hline No & $72(96.0 \%)$ & $50(96.2 \%)$ & \\
\hline Renal & & & 0.772 \\
\hline Yes & $5(6.7 \%)$ & $2(3.8 \%)$ & \\
\hline No & 70 (93.3\%) & 50 (96.2\%) & \\
\hline Diabetes & & & 0.566 \\
\hline Yes & $13(17.3 \%)$ & $12(23.1 \%)$ & \\
\hline No & $62(82.7 \%)$ & 40 (76.9\%) & \\
\hline Histological type & & & 0.794 \\
\hline Adenocarcinoma & $42(56.0 \%)$ & $29(55.8 \%)$ & \\
\hline Squamous cell carcinoma & $30(40.0 \%)$ & $22(42.3 \%)$ & \\
\hline Other & $3(4.0 \%)$ & $\mathrm{I}(1.9 \%)$ & \\
\hline Tumor location & & & 0.826 \\
\hline Upper third & $5(6.7 \%)$ & $3(5.8 \%)$ & \\
\hline Middle third & 14 (18.7\%) & $12(23.1 \%)$ & \\
\hline Lower third & $56(74.6 \%)$ & 37 (7I.l\%) & \\
\hline Percentage of circumference involved & & & 0.110 \\
\hline $0 \%-25 \%$ & $6(8.0 \%)$ & $0(0.0 \%)$ & \\
\hline $25 \%-50 \%$ & $5(6.7 \%)$ & $2(3.8 \%)$ & \\
\hline $50 \%-75 \%$ & $5(6.7 \%)$ & $6(11.6 \%)$ & \\
\hline $75 \%-100 \%$ & $42(56.0 \%)$ & $36(69.2 \%)$ & \\
\hline No information & 17 (22.6\%) & $8(15.4 \%)$ & \\
\hline
\end{tabular}

Abbreviation: BMI, body mass index.

with no patients with metastases receiving RT alone. Other interventions performed subsequent to CT and/or RT were stenting, dilatation, and feeding jejunostomies. The details of these treatments, including CT or RT-related morbidity and mortality are summarized in Table 3.

\section{Survival}

Kaplan-Meier survival analysis showed a median survival of 10.8 months for the total population. There was a significant difference in survival ( $\mathrm{p}<0.001$ ) between the groups with versus without metastases, with a median survival in the group without metastases of 13.6 months versus 6.5 months in the group with metastases (Figure 1). No difference between histological subtypes were found (median survival for adenocarcinoma 10.8 months and for SCC 11.7 months, $\log$ rank test; $\mathrm{p}=0.507$ ).

The five-year survival for patients undergoing treatment for localized disease was $12 \%$. 
Table 2 Symptoms and results of palliation of all patients $(n=127)$

\begin{tabular}{|c|c|c|c|}
\hline & $\begin{array}{l}\text { Nonmetastatic } \\
n=75\end{array}$ & $\begin{array}{l}\text { Metastatic } \\
n=52\end{array}$ & $\mathbf{p}$ \\
\hline \multicolumn{4}{|l|}{ Dysphagia } \\
\hline Yes & $64(85.3 \%)$ & $50(96.2 \%)$ & 0.093 \\
\hline No & II (I4.7\%) & $2(3.8 \%)$ & \\
\hline Palliation of dysphagia & & & 0.036 \\
\hline Completely & $22(34.3 \%)$ & $10(20.0 \%)$ & \\
\hline Partial & 19 (29.7\%) & 22 (44.0\%) & \\
\hline No palliation & $6(9.4 \%)$ & $12(24.0 \%)$ & \\
\hline No information & I7 (26.6\%) & $6(12.0 \%)$ & \\
\hline Pain & & & 0.040 \\
\hline Yes & 14 (18.7\%) & 19 (36.5\%) & \\
\hline No & 61 (8I.3\%) & $33(63.5 \%)$ & \\
\hline Palliation of pain & & & 0.011 \\
\hline Completely & $6(42.9 \%)$ & $3(15.8 \%)$ & \\
\hline Partial & $0(0.0 \%)$ & $6(31.6 \%)$ & \\
\hline No palliation & $0(0.0 \%)$ & $3(15.8 \%)$ & \\
\hline No information & 8 (57.1\%) & 7 (36.8\%) & \\
\hline Bleeding & & & 0.998 \\
\hline Yes & $6(8.0 \%)$ & $5(9.6 \%)$ & \\
\hline No & $69(92.0 \%)$ & 47 (90.4\%) & \\
\hline Palliation of bleeding & & & 1.00 \\
\hline Completely & $6(100.0 \%)$ & $5(100.05)$ & \\
\hline Partial & $0(0.0 \%)$ & $0(0.0 \%)$ & \\
\hline No palliation & $0(0.0 \%)$ & $0(0.0 \%)$ & \\
\hline No information & $0(0.0 \%)$ & $0(0.0 \%)$ & \\
\hline
\end{tabular}

There was no survival difference for different histological subtypes within the group without metastases (Figure 2), with a median survival of 13.1 months in patients with adenocarcinoma versus 14.5 months in those with SCC $(p=0.897)$.

Patients with metastases had no five-year survival. The survival analysis stratified according to histological type is shown in Figure 3. No significant differences between adenocarcinoma and SCC were identified. Median survival for patients with adenocarcinoma was 6.2 months compared to 9.3 months in patients with $\mathrm{SCC}(\mathrm{p}=0.429)$. Survival was similar for patients with metastases to distant sites versus nonregional lymph nodes and five-year survival was 0 in both subgroups. Median survival for patients with distant metastasis was 6.5 months compared to 7.7 months in patients with nonregional lymph-node metastasis $(\mathrm{p}=0.847)$.

\section{Subgroup analysis of patients who received combined CRT treatment}

Eighty-seven (68.5\%) patients received combined CRT therapy. The details for these patients are shown in Table 4.
Except for age, which was again significantly higher in the group without metastases, the data was similar to the overall group. The median survival for patients without metastases was 13.6 months versus 6.5 months in patients with metastases $(p<0.001)$ and with five-year survival of $0 \%$ and $12.2 \%$, respectively. Subgroup analysis stratified according the histological subtype showed no survival difference between the groups with versus without metastases. The results were similar to the overall group of patients, with median survival times of 5.9 months for adenocarcinoma and 6.5 months for SCC $(\mathrm{p}=0.515)$ in the group with metastases and 12.5 months for adenocarcinoma and 15.2 months for SCC $(p=0.688)$ in the group without metastases.

\section{Discussion}

The majority of patients presenting with esophageal cancer do not undergo surgical resection, either because they have metastatic disease at presentation, or they are unsuitable for surgery because of age, co-morbidity, or locally invasive disease. Many studies have been published which address the use of CT with or without RT in such patients. However, the outcomes of various studies vary considerably, because of the treatment regimens evaluated, different tumor stages treated, the proportion of patients with metastatic disease, and the histopathological subtypes treated. Additionally, many studies report only a modest number of patients, and are reports of initial experience with novel CT regimens, rather than reports of outcomes using the conventional treatments which are applied in day to day clinical practice. . $, 5,7-13,18-20^{-1}$ Furthermore, previous studies fail to stratify outcomes for metastatic versus nonmetastatic esophageal cancer in patients undergoing nonsurgical treatment. Such stratification allows the outcome of two distinct clinical presentations to be determined. As presence of metastases is one of the major predictors for survival, grouping according to the presence or absence of metastatic disease at diagnosis makes sense, and knowing the outcome for these scenarios allows surgeons to convey to patients accurate information about treatment outcomes. ${ }^{14,15}$

There was a significant age difference between the study groups, with patients with metastatic disease being younger. However, age was not a prognostic indicator for death. Possible explanations for this finding might be that cancer is more aggressive when it develops in younger patients, or the fact that younger patients with nonmetastatic disease were more likely to receive surgical treatment in our institutions. 
Table 3 Treatment parameters of all patients $(n=127)$

\begin{tabular}{|c|c|c|c|}
\hline & Nonmetastatic $n=75$ & Metastatic $\mathbf{n}=\mathbf{5 2}$ & $\mathbf{p}$ \\
\hline Type of therapy & & & 0.0097 \\
\hline Chemotherapy alone & $16(21.3 \%)$ & $12(23.1 \%)$ & \\
\hline Radiotherapy alone & $12(16.0 \%)$ & $0(0.0 \%)$ & \\
\hline Combined & 47 (62.7\%) & 40 (76.9\%) & \\
\hline Chemo- or radiotherapy-related morbidity & & & 0.422 \\
\hline Yes & $28(37.3 \%)$ & $15(28.8 \%)$ & \\
\hline No & $47(62.7 \%)$ & 37 (7I.2\%) & \\
\hline Hepatic & 2 & 1 & \\
\hline Renal & 1 & 0 & \\
\hline Radiation esophagitis & 20 & 12 & \\
\hline Neutropenia requiring treatment & 2 & 1 & \\
\hline Other & 3 & 1 & \\
\hline Chemo- or radiotherapy-related mortality & & & 0.747 \\
\hline Yes & $2(2.7 \%)$ & $\mathrm{I}(\mathrm{I} .9 \%)$ & \\
\hline No & $73(97.3 \%)$ & $5 \mathrm{I}(98.1 \%)$ & \\
\hline Stenting undertaken later & & & 0.566 \\
\hline Yes & $13(17.3 \%)$ & $12(23.1 \%)$ & \\
\hline No & $62(82.7 \%)$ & $40(76.9 \%)$ & \\
\hline Dilatation undertaken later & & & 0.329 \\
\hline Yes & II (I4.7\%) & $12(23.1 \%)$ & \\
\hline No & $64(85.3 \%)$ & $40(76.9 \%)$ & \\
\hline Feeding jejunostomy undertaken later & & & 0.384 \\
\hline Yes & $9(12.0 \%)$ & $10(19.2 \%)$ & \\
\hline No & 66 (88.0\%) & 42 (80.8\%) & \\
\hline
\end{tabular}

In our study, the majority of patients $(68 \%)$ received treatment with 5-FU and cisplatin, combined with RT of 50.4 Gy. This is probably the commonest CRT treatment regimen currently used in Australia for the treatment of patients with esophageal cancer who are not undergoing

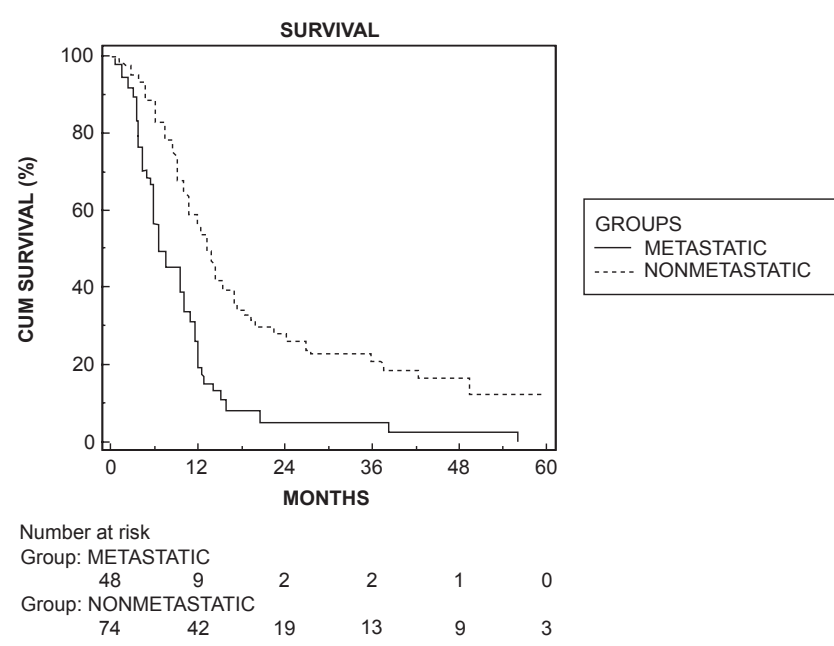

Figure I Kaplan-Meier survival curve of the two groups. There was a significant difference in survival in favor of the nonmetastatic group (log rank test, $\mathrm{p}<0.00 \mathrm{I}$ ). surgical resection. In the group without metastatic disease, $21 \%$ received CT alone (also 5-FU and cisplatin), and 16\% of patients received RT alone. In the group with metastatic disease, all patients in this study received CT, and most (77\%) in combination with RT. Whilst this variability of treatment

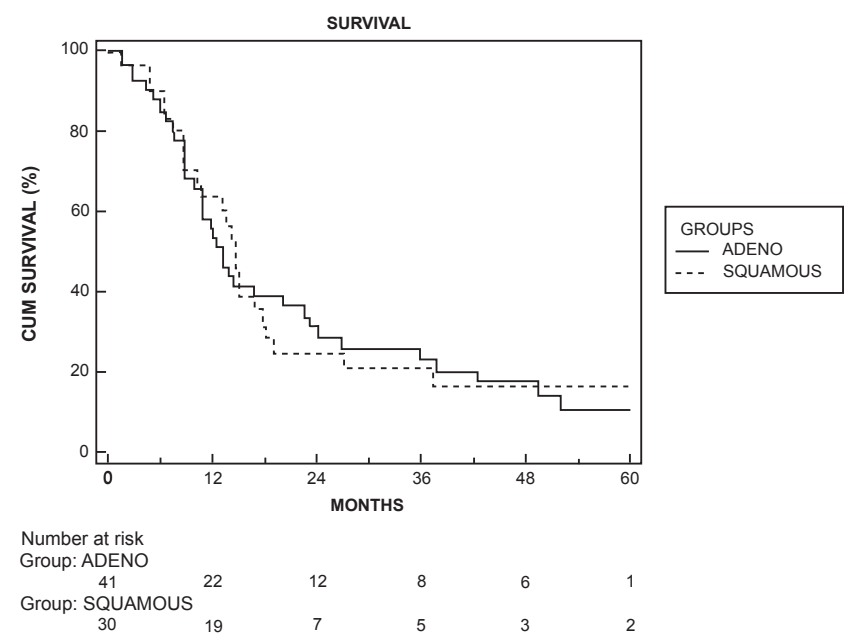

Figure 2 Kaplan-Meier survival curve for the nonmetastatic group stratified by histological types. There was no significant difference in survival (log rank test, $p=0.897$ ). 


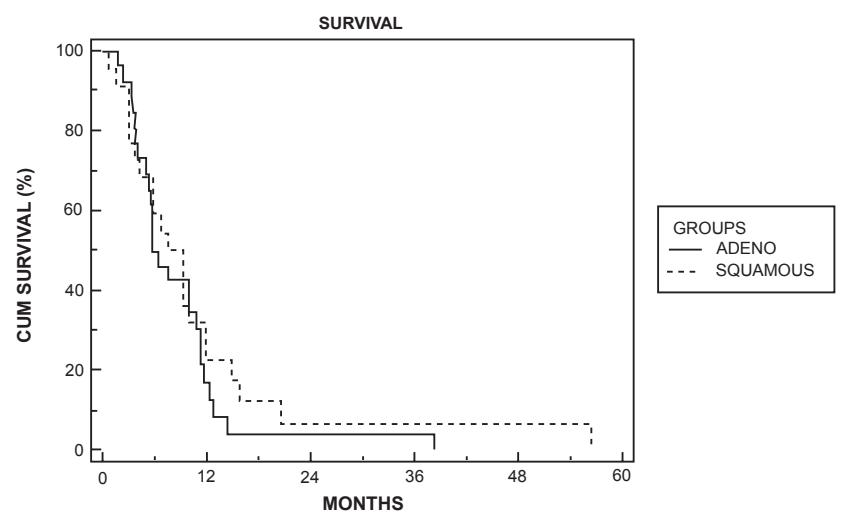

Number at risk

$\begin{array}{llllll}\begin{array}{l}\text { Group: ADENO } \\ 26\end{array} & 4 & 1 & 1 & 0 & 0 \\ \text { Group: SQUAMOUS } & & 1 & 1 & 1 & 1\end{array}$

Figure 3 Kaplan-Meier survival curve for the metastatic group stratified by histological type. There was no significant difference in survival (log rank test, $p=0.429$ ).

regimes is a potential source of bias in this study, the variation in actual treatments reflects clinical practice rather than a clinical trial protocol, and the results of our study still inform clinical decision making. Furthermore, the subgroup analysis which compared the outcome for patients who received combined CRT with patients who had monotherapy (CT or RT alone) revealed similar survival outcomes.

Not surprisingly, we saw a significant difference in survival outcomes for patients with metastatic versus nonmetastatic esophageal cancer. The five-year survival for patients presenting with localized disease was $12 \%$, whereas almost no patients with metastases survived for five years. These data are comparable with other reports of patients undergoing definitive CRT., ${ }^{6,18}$ Furthermore, all patients with localized disease had poor prognosis T-stage T3 or T4 tumors at presentation, and this survival data should be considered when discussing with patients the pros and cons of surgical resection for advanced esophageal cancer. The outcome of definitive CRT in patients with nonmetastatic tumors is almost certainly inferior to multimodal treatment which includes surgery, where five-year survival rates over $30 \%$ have been reported, although direct comparisons between studies can be difficult, as post-surgical survivals in most series are almost certainly favorably influenced by the inclusion of some patients with earlier stage disease. ${ }^{21-24}$ Two recent studies evaluating CRT with or without surgery have suggested no benefit for multimodal treatment including surgery. ${ }^{25,26}$ However, these studies have only evaluated SCC. One of these studies only determined two-year survival, and whilst the other reported equivalent overall survival, local progression-free survival was better following
Table 4 Descriptives of the subgroup of patients who underwent combined chemoradiotherapy $(n=87)$

\begin{tabular}{|c|c|c|c|}
\hline & $\begin{array}{l}\text { Nonmetastatic } \\
n=47\end{array}$ & $\begin{array}{l}\text { Metastatic } \\
n=40\end{array}$ & $\mathbf{p}$ \\
\hline $\begin{array}{l}\text { Median age at } \\
\text { diagnosis (range) }\end{array}$ & $75.9(46.3-90.6)$ & $66.5(32.8-87.8)$ & $<0.001$ \\
\hline Gender & & & 0.083 \\
\hline Male & 33 & 24 & \\
\hline Female & 14 & 16 & \\
\hline \multicolumn{4}{|l|}{ Comorbidity } \\
\hline Cardiac & & & 0.112 \\
\hline Yes & 24 & 15 & \\
\hline No & 23 & 25 & \\
\hline Pulmonary & & & 0.083 \\
\hline Yes & 14 & 6 & \\
\hline No & 33 & 34 & \\
\hline Hepatic & & & 0.315 \\
\hline Yes & 3 & 1 & \\
\hline No & 44 & 39 & \\
\hline Renal & & & 0.817 \\
\hline Yes & 2 & 2 & \\
\hline No & 45 & 38 & \\
\hline Diabetes & & & $0.07 I$ \\
\hline Yes & 9 & 11 & \\
\hline No & 38 & 29 & \\
\hline Histological type & & & 0.604 \\
\hline Adenocarcinoma & 25 & 22 & \\
\hline $\begin{array}{l}\text { Squamous cell } \\
\text { carcinoma }\end{array}$ & 20 & 18 & \\
\hline Other & 2 & 0 & \\
\hline Tumor location & & & 0.825 \\
\hline Upper third & 4 & 2 & \\
\hline Middle third & 11 & 11 & \\
\hline Lower third & 32 & 27 & \\
\hline $\begin{array}{l}\text { Chemo- or } \\
\text { radiotherapy- } \\
\text { related morbidity }\end{array}$ & & & 0.704 \\
\hline Yes & 17 & 12 & \\
\hline No & 30 & 28 & \\
\hline $\begin{array}{l}\text { Chemo- or } \\
\text { radiotherapy- } \\
\text { related mortality }\end{array}$ & & & 0.547 \\
\hline Yes & 1 & 1 & \\
\hline No & 39 & 46 & \\
\hline
\end{tabular}

surgery, and surgery was associated with a significantly lower treatment-related mortality outcome. ${ }^{24,26}$

Treatment-related morbidity was significant, being 34\% in our study. Treatment-related mortality was $2.4 \%$, and this is comparable to other series which report morbidity 
and mortality rates of $4.0 \%$ and $3.5 \%$, respectively. ${ }^{27-29}$ These mortality rates are not significantly lower than for patients undergoing esophagectomy, although patients undergoing surgery, are on average likely to be fitter than those who are refused surgery because of co-morbidity, and hence morbidity and mortality cannot be validly compared. Nevertheless, the data do highlight the risks of nonsurgical treatment. $^{30}$

Pre-treatment dysphagia was present in a majority of patients, and more frequently than previously described. ${ }^{2}$ Dysphagia was not assessed with a score. All patients had clinical follow-up after treatment by the medical oncologists, but this usually stopped when the care was transferred to palliative care. This might have resulted in under-reporting of post-treatment dysphagia, especially when dysphagia reoccurred and patients were under the care of the palliative team. Almost all patients with metastatic tumors reported dysphagia. Palliation of dysphagia with RT/CT was less often achieved in patients with metastatic disease, and pain was also more frequent in these patients and less often palliated. Also, CT alone was less effective for the palliation of dysphagia than combination treatment, highlighting the importance of RT in patients who present with dysphagia. However, in this cohort omission of RT did not result in a higher number of patients requiring stenting or dilatation.

A number of the patients needed additional interventions such as an esophageal stent, endoscopic dilatation, or feeding jejunostomy. The likelihood of needing one of these interventions was not influenced by presence or absence of metastatic disease at the time of treatment. RT/CT achieves good palliation of tumor related symptoms. ${ }^{31,32}$ Our results suggest that excellent palliation of dysphagia was achieved in most patients and only a minority subsequently required palliation with an endoscopic stent.

\section{Conclusion}

Patients with esophageal cancer who do not undergo esophagectomy will usually benefit from CRT, supported by interventions such as stenting and dilatation. Nevertheless, treatment related morbidity is not insubstantial. In patients with localized disease at diagnosis, long term survival can be achieved in approximately $12 \%$ of patients, whereas fiveyear survival is very rare in patients with metastatic disease at presentation.

\section{Disclosure}

The authors received no financial support and report no conflicts of interest in this work.

\section{References}

1. Falk J, Carstens H, Lundell L, Albersson M. Incidence of carcinoma of the esophagus and gastric cardia. Changes over time and geographical differences. Acta Oncol. 2007;46:1070-1074.

2. Enzinger PC, Mayer RJ. Esophageal cancer. N Engl J Med. 2003;349: 2241-2252.

3. Ra J, Paulson EC, Kucharczuk J, et al. Postoperative mortality after esophagectomy for cancer: development of a preoperative risk prediction model. Ann Surg Oncol. 2008;15:1577-1584.

4. Cooper JS, Guo MD, Herskovic A, et al. Chemoradiotherapy of locally advanced esophageal cancer: long-term follow-up of a prospective randomized trial (RTOG 85-01). JAMA. 1999;281:1623-1627.

5. Kumar S, Dimri K, Khurana R, Rastogi N, Das KJ, Lal P. A randomised trial of radiotherapy compared with cisplatin chemo-radiotherapy in patients with unresectable squamous cell cancer of the esophagus. Radiother Oncol. 2007;83:139-147.

6. Liao Z, Cox JD, Komaki R. Radiotherapy of esophageal cancer. J Thorac Oncol. 2007;2:553-568.

7. Slabber CF, Nel JS, Schoeman L, Burger W, Falkson G, Falkson CI. A randomized study of radiotherapy alone versus radiotherapy plus 5 -fluorouracil and platinum in patients with inoperable, locally advanced squamous cancer of the esophagus. Am J Clin Oncol. 1998;21: 462-465.

8. Harney J, Goodchild K, Phillips H, Glynne-Jones R, Hoskin PJ, Saunders MI. A phase I/II study of CHARTWEL with concurrent chemotherapy in locally advanced, inoperable carcinoma of the oesophagus. Clin Oncol (R Coll Radiol). 2003;15:109-114.

9. Chiarion-Sileni V, Corti L, Ruol A, et al. Phase II trial of docetaxel, cisplatin and fluorouracil followed by carboplatin and radiotherapy in locally advanced esophageal cancer. Br J Cancer. 2007;96:432-438.

10. Ohtsu A, Boku N, Muro K, et al. Definitive chemoradiotherapy for T4 and/or M1 lymph node squamous cell carcinoma of the esophagus. J Clin Oncol. 1999;17:2915-2921.

11. Jatoi A, Murphy BR, Foster NR, et al. North Central Cancer Treatment Group. Oxaliplatin and capecitabine in patients with metastatic adenocarcinoma of the esophagus, gastroesophageal junction and gastric cardia: a phase II study from the North Central Cancer Treatment Group. Ann Oncol. 2006;17:29-34.

12. Jatoi A, Dakhil SR, Foster NR, et al. Bortezomib, paclitaxel, carboplatin as a first line regimen for patients with metastatic esophageal, gastric and gastresophageal cancer: phase II results from the North Central Cancer Treatment Group (N044B). J Thorac Oncol. 2008;3:516-520.

13. Cho SH, Shim HJ, Lee SR, et al. Concurrent chemoradiotherapy with S-1 and cisplatin in advanced esophageal cancer. Dis Esophagus. 2008;21:697-703

14. Bergquist H, Johnsson A, Hammerlid E, Wenger U, Lundell 1, Ruth M. Factors predicting survival in patients with advanced esophageal cancer: a prospective multicentre evaluation. Aliment Pharmacol Ther. 2008;27:385-395.

15. Di Fiore F, Lecleire S, Rigal O, et al. Predictive factors of survival in patients treated with definitive chemoradiotherapy for squamous cell esophageal cancer. World J Gastroenterol. 2006;12:4185-4190.

16. Tougeron D, Di Fiore F, Hamidou H, Rigal O, Paillot B, Michel P. Response to definite chemoradiotherapy and survival in patients with an esophageal adenocarcinoma versus squamous cell carcinoma: a matched pair analysis. Oncology. 2007;73:328-334.

17. Webb A, Cunningham D, Scarffe JH, et al. Randomized trial comparing epirubicin, cisplatin, and fluorouracil versus fluorouracil, doxorubicin, and methotrexate in advanced esophagogastric cancer. J Clin Oncol. 1997; 15:261-267

18. Geh JI. The use of chemoradiotherapy in esophageal cancer. Eur $J$ Cancer. 2002;38:300-313.

19. Nishimura Y, Suzuki M, Nakamatsu K, Kanamori S, Yagyu Y, Shigeoka H. Prospective trial of concurrent chemoradiotherapy with protracted infusion of 5-fluorouracil and cisplatin for T4 esophageal cancer with or without fistula. Int J Radiat Oncol Biol Phys. 2002;53:134-139. 
20. Mackay HJ, McInnes A, Paul J, et al. A phase II study of epirubicin, cisplatin and raltitrexed combination chemotherapy (ECT) in patients with advanced oesophageal and gastric adenocarcinoma. Ann Oncol. 2001;12:1407-1410.

21. Hulscher JB, van Sandick JW, de Boer AG, et al. Extended transthoracic resection compared with limited transhiatal resection for adenocarcinoma of the esophagus. $N$ Engl J Med. 2002;347:1662-1669.

22. Lerut T, Nafteux P, Moons J, et al. Three-field lymphadenectomy for carcinoma of the esophagus and gastroesophageal junction in $174 \mathrm{R} 0$ resections: impact on staging, disease-free survival, and outcome: a plea for adaptation of TNM classification in upper-half esophageal carcinoma. Ann Surg. 2004;240:962-972; discussion, 972-974.

23. Wijnhoven BP, Tran KT, Esterman AJ, Watson DI, Tilanus HW. An evaluation of prognostic factors and tumor staging of resected carcinoma of the esophagus. Ann Surg. 2007;245:717-725.

24. Thompson SK, Ruszkiewicz AR, Jamieson GG, et al. Improving the accuracy of TNM staging in esophageal cancer: a pathological review of resected specimens. Ann Surg Oncol. 2008;15:1337-1358.

25. Bedenne 1, Michel P, Bouche O, et al. Chemoradiation followed by surgery compared with chemoradiation alone in squamous cancer of the esophagus: FFCD 9102. J Clin Oncol. 2007;25:1160-1168.

26. Stahl M, Stuschke M, Lehmann N, et al. Chemoradiation with or without surgery in patients with locally advanced squamous cell carcinoma of the esophagus. J Clin Oncol. 2005;23:2310-2317.
27. Kaneko K, Ito H, Konishi K, et al. Definitive chemoradiotherapy for patients with malignant stricture due to T3 or T4 squamous cell carcinoma of the esophagus. Br J Cancer. 2003;88:18-24.

28. Ishikura S, Nihei K, Ohtsu A, et al. Long-term toxicity after definitive chemoradiotherapy for squamous cell carcinoma of the thoracic esophagus. J Clin Oncol. 2003;21:2697-2702.

29. Kassam Z, Wong RK, Ringash J, et al. A phase II/III study to evaluate toxicity and efficacy of accelerated fractionation radiotherapy for the palliation of dysphagia from carcinoma of the esophagus. Clin Oncol (R Coll Radiol). 2008;20:53-60.

30. Schneider PM, Baldus SE, Metzger R, et al. Histomorphologic tumor regression and lymph node metastasis determine prognosis following neoadjuvant radiochemotherapy for esophageal cancer. Ann Surg. 2005;242:684-692.

31. Wong SK, Chiu PW, Leung SF, et al. Concurrent chemoradiotherapy or endoscopic stenting for advanced squamous cell carcinoma of the esophagus: a case-control study. Ann Surg Oncol. 2007;15: 576-582.

32. Javle M, Ailawadhi S, Yang GY, Nwogu CE, Schiff MD, Nava HR. Palliation of malignant dysphagia in esophageal cancer: a literaturebased review. J Support Oncol. 2006;4:365-375.

33. Gockel I, Kneist W, Junginger T. Incurable esophageal cancer: patterns of tumor spread and therapeutic consequences. World J Surg. 2006;30:183-190.
Clinical and Experimental Gastroenterology

\section{Publish your work in this journal}

Clinical and Experimental Gastroenterology is an international, peerreviewed, open access journal, publishing all aspects of gastroenterology in the clinic and laboratory, including: Pathology, pathophysiology of gastrointestinal disease; Investigation and treatment of gastointestinal disease; Pharmacology of drugs used in the alimentary tract;

\section{Dovepress}

Immunology/genetics/genomics related to gastrointestinal disease. This journal is indexed on CAS. The manuscript management system is completely online and includes a very quick and fair peer-review system. Visit http://www.dovepress.com/testimonials.php to read real quotes from published authors.

Submit your manuscript here: http://www.dovepress.com/clinical-and-experimental-gastroenterology-journal 